American Journal of Pharmaceutical Education 2019; 83 (6) Article 6809.

\title{
RESEARCH
}

\section{Investigating Whether Transfer of Learning in Pharmacy Students Depends More on Knowledge Storage or Accessibility}

\author{
Adam M. Persky, PhD, ${ }^{\text {a,b }}$ Kimberly Murphy, $\mathrm{BS}^{\mathrm{a}}$ \\ ${ }^{a}$ UNC Eshelman School of Pharmacy, University of North Carolina at Chapel Hill, Chapel Hill, North Carolina \\ ${ }^{\mathrm{b}}$ Associate Editor, American Journal of Pharmaceutical Education, Arlington, Virginia
}

Submitted September 22, 2017; accepted February 15, 2018; published August 2019.

\begin{abstract}
Objective. To investigate whether prior knowledge or reactivated marginal knowledge alone is sufficient for student pharmacists to transfer foundational science content to pharmacy application.

Methods. In two experiments, transfer of foundational science knowledge was examined. Far transfer was examined by investigating the relationship between prior knowledge of chemistry and physiology to pharmacokinetic application. Near transfer was examined by investigating the relationship between foundational physiology content and its application to pharmacy. Participants completed fill-in-theblank (FIB) items to assess accessible prior knowledge. Half the participants also received multiplechoice formats of the FIB questions to assess stored well but not readily retrievable information. Participants then answered application-type questions.

Results. Participants were more successful in correctly answering multiple-choice questions than FIB questions. Participants could not apply stored and accessible nor stored but inaccessible knowledge in the far transfer condition (pharmacokinetics application). Participants were more successful in applying foundational science knowledge to the near transfer condition (pharmacy application of physiology)

Conclusion. This study suggests some students may be able to transfer their prerequisite knowledge to pharmacy application, but most students probably cannot successfully transfer without formal instruction. In addition, reactivating the foundational knowledge through multiple-choice testing has been shown to be sufficient to cause retention of the knowledge, but this seems to be an insufficient stimulus to allow for transfer to occur. What this confirms is that even if students have the prior knowledge, transfer cannot be assumed to be an automatic process and probably requires specific instruction.
\end{abstract}

Keywords: transfer, prior knowledge, marginal knowledge, physiology, pharmacokinetics

\section{INTRODUCTION}

While pursuing a health professions education, students must attempt to take their current knowledge into new learning environments and use that information to solve patient-related problems. An inability to apply knowledge to a new situations may be the result of a lack of prior learning (ie, they never knew it), an inability to access prior knowledge because of disuse (ie, be in a "tip of a tongue" state), the features of the patient-related problem itself (ie, they do not recognize the underlying problem), or an inability to reason through a novel application of previously acquired knowledge. ${ }^{1-3}$ The purpose

Corresponding Author: Adam M. Persky, 2312 Kerr Hall, CB\#7569, Division of Pharmacotherapy and Experimental Therapeutics, Eshelman School of Pharmacy, University of North Carolina at Chapel Hill, Chapel Hill, NC 27599. Tel: 919-966-9104. E-mail: apersky@unc.edu of this study was to investigate the role of prior knowledge and its accessibility (ie, generate a response when needed) in the transfer of learning.

Faculty members must help learners overcome three types of knowledge transfer issues that learners may face: moving from prior knowledge to new learning; from new learning to new situations (ie, preparing for future learning); and from learning to application (ie, clinical practice). ${ }^{3}$ Learning refers to the ability to acquire, retain, retrieve, and apply information to solve future problems. ${ }^{4}$ The ability to apply knowledge and skills to a future or novel problem is referred to as transfer. In graduate or professional education, transfer depends on the foundational knowledge obtained through prerequisite education. For PharmD programs, as well as other health professions curricula, a substantial amount of prerequisite coursework is required for matriculation and a significant portion of this coursework is in the foundational 


\section{American Journal of Pharmaceutical Education 2019; 83 (6) Article 6809.}

sciences (eg, physiology, chemistry, math). The science coursework includes a broad scope of knowledge, which must then be more narrowly applied within the graduate or professional program. This ability to utilize previous concepts to solve more focused and specific problems can be challenging for students. Similarly, identifying ways to help students' access and transfer that knowledge is also a challenge for instructors.

In this study, we examined both near and far transfer problems. The transferability of knowledge depends on the features of a problem. These features could be in close similarity to the original problem where learning initially occurred, which is referred to as near transfer. Problem features could also be more dissimilar to the original problem, which is referred to as far transfer. Near transfer occurs more readily when a problem looks the same as a problem encountered in prerequisite coursework, or when a problem looks different but contains the same structural features as the previously encountered problem. ${ }^{1,5}$ Many educators hypothesize that learners will successfully achieve near transfer with high frequency. Far transfer requires a deeper level of understanding to connect and apply previously learned knowledge to a never-before-seen situation. ${ }^{1,5}$ The surface and structural features of a problem may rest outside of those seen by the student previously, and therefore far transfer is required for problem-solving. ${ }^{1}$ One goal of graduate and professional coursework is for students to achieve both near and far transfer for further application of knowledge in a professional setting. In this study, near transfer was examined in the context of the link between foundational physiology knowledge and "pharmacetized" physiological application. Far transfer was explored in terms of the link between foundational chemistry and physiology content and pharmacokinetic problems.

We designed this study to examine students' ability to transfer knowledge that has a high storage strength and high retrieval strength, as well as their ability to transfer reactivated marginal knowledge, ie, knowledge that has a high storage strength but low retrieval strength. Failure to transfer knowledge may have several root causes, but one reason that is often neglected is the student did not learn a concept initially, or the student learned the concept initially but cannot access that information when necessary. ${ }^{1,3}$ Forgetting can occur quickly after learning. ${ }^{6}$ This results in differences in the retention and accessibility of stored knowledge (ie, how easily it can be retrieved). Knowledge may be stored well (ie, high storage strength) or stored poorly (ie, low storage strength), and that knowledge may be readily retrievable (ie, high retrieval strength) or poorly retrievable (ie, low retrieval strength). ${ }^{7}$ Instructors expect students who pur- sue graduate and professional level education to have prerequisite knowledge with high storage strength and may assume that students' knowledge has high retrieval strength as well. However, their retrieval strength will likely be low because of lack of recent use of that knowledge, ie, it may have been several years since the learner completed the prerequisite courses. As defined above, marginal knowledge is knowledge that has high storage strength but low retrieval strength. A goal of the instructor is to reactivate and stabilize the student's ability to retrieve that knowledge, and then subsequently build upon that knowledge with a more focused approach on its application in the profession. Currently, the only documented method for stabilizing access to this marginal knowledge is through multiple-choice testing. ${ }^{8-10}$

Taken together, the present study seeks to explore whether students can spontaneously transfer prerequisite knowledge to solve physiological problems and basic pharmacokinetic problems, and whether their retrievability strength influences that ability. Findings from this study may be helpful in designing graduate and professional courses by providing information on potential sticking points in students transferring their knowledge to pharmacy application.

\section{METHODS}

The participants in experiment 1 were student pharmacists enrolled in a foundational pharmacokinetics course in the second semester of their first year. Prior to this course, the student pharmacists had completed a three-week intensive Pharmacy Bridging Course (PBC), which reviewed selected foundational concepts in chemistry, biochemistry, and physiology. ${ }^{11}$ Students had also completed courses in pathophysiology and a molecular basis for drug action (ie, medicinal chemistry) prior to taking the pharmacokinetics course.

A different cohort of student pharmacists, enrolled in the PBC, participated in experiment 2. The two cohorts of student pharmacists were similar in terms of admissions criteria. Prior to enrolling, student pharmacists were required to have taken prerequisite courses through Organic Chemistry II as well as one semester of anatomy and physiology.

In experiment 1, a 25-question assessment consisting of 10 fill-in-the-blank questions regarding foundational knowledge about chemistry and physiology was used that directly related to the pharmacokinetic course content and were previously covered in the PBC they had just completed. For five of the 10 fill-in-the-blank questions, there was a "sister" multiple-choice question, ie, a multiplechoice version of the fill-in-the-blank question (Appendix 1). The multiple-choice questions served to reactivate 


\section{American Journal of Pharmaceutical Education 2019; 83 (6) Article 6809.}

student pharmacists' marginal knowledge. Each multiple-choice question had three answer choices and directly followed the respective fill-in-the-blank question. The five multiple-choice-questions were counterbalanced, ie, half-the class received multiple-choice versions of questions 1 through 5 while the other half received multiple-choice versions of questions 6 through 10 . The experimental condition consisted of those questions with the multiple-choice versions (to reactivate marginal knowledge) and the control condition consisted of the questions that did not have the multiple-choice version. The remainder of the assessment consisted of 10 pharmacokinetic application questions (eight fill-in-the-blank and two multiple-choice questions) that aligned with the foundational chemistry and physiology questions. The mixture of question types was consistent with the format of the course assessments This assessment occurred on the first day of class in the Pharmacokinetics course (second semester, first year). The assessment was administered using ExamSoft (ExamSoft, Worldwide, Dallas, TX) without backward navigation (ie, students saw the fillin-the-blank question first and then the multiple-choice version of the same question, but could not go back to change answers). During the final examination (administered about 15 weeks later), these 10 pharmacokineticsrelated questions were repeated but in a paper-and-pen format.

Experiment 2 followed the same procedure as experiment 1 except it occurred on the first day of the Pharmacy Bridging Course and the final examination was administered three weeks after the initial test. In this second experiment the assessment was 50-questions that included 20 fill-in-the-blank questions regarding foundational knowledge about physiology, which students were supposed to have covered in required prerequisite courses prior to entering the PharmD program This assumption was based on a review of several undergraduate syllabi. This assessment included 10 multiple-choice versions of the fill-in-the-blank questions, each with three answer choices, ie, the respective multiple-choice question directly followed its sister fill-in-the-blank question. Like in experiment 1 , these questions were counterbalanced within the participants. The assessment ended with 20 application questions, 16 multiple-choice questions (each with three answer options), and four fill-in-the-blank questions. These questions could be linked backwards to other content on which students had been tested, and the mixture of question types was consistent with the format of the course assessments. The procedure for both experiments is outlined in Figure 1.

This study had a within-subjects design. Paired $t$ tests were performed to compare the control to the experimental conditions (IBM SPSS Statistics for Windows, Version 24.0, Armonk, NY). Performance on the applied questions was conditionalized for correct responses on the fill-in-the-blank and multiple-choice responses, and odds ratios were calculated. When appropriate, Cohen $d$ was used to calculate an effect size. Significance was set at $p<.05$. This study was approved by the University of North Carolina at Chapel Hill's Institutional Review Board.

\section{RESULTS}

The conditions, meanings of each condition, and results are presented in Table 1. We first assessed the student's ability to successfully retrieve assumed prior knowledge from prerequisite course work (Table 2). In experiment 1 , the average grade was $36 \%(\mathrm{SD}=17 \%)$ and there was no significant difference between the control and experimental conditions. In experiment 2 , the average grade was $23 \%(\mathrm{SD}=29 \%)$ and there was a small significant difference between the control and experimental conditions $(d=.20)$. In both cases, about $65 \%$ to $75 \%$ of the tested information appeared to be forgotten, never learned, or inaccessible.

We then assessed the students' ability to correctly answer multiple-choice versions of prerequisite knowledge (Table 3 ). In experiment 1 , performance on the

\section{Control}

\begin{tabular}{|c|c|c|}
$\begin{array}{c}\text { Fill-in-the-blank } \\
\text { Foundational Material }\end{array}$ & $\begin{array}{c}\text { Fill-in-the-blank or MCQ } \\
\text { Applied Material }\end{array}$ \\
\hline
\end{tabular}

\section{Experimental}

\begin{tabular}{|c|c|c|c|}
$\begin{array}{c}\text { Fill-in-the-blank } \\
\text { Foundational Material }\end{array}$ & $\sqrt{\begin{array}{c}\text { Mill-in-the-blank or MCQ } \\
\text { Applied Material }\end{array}}$ \\
\hline
\end{tabular}

Figure 1. Diagram of Study Design. Participants had to generate a response on the foundational science material. Half the material was available as multiple-choice questions (MCQ) to reactivate marginal knowledge. The transfer tasks were either fill-in-theblank or multiple-choice questions (MCQ). 


\section{American Journal of Pharmaceutical Education 2019; 83 (6) Article 6809.}

Table 1. Interpretation of Experimental Conditions and Summary of Study Results. Fill-in-the-blank tests the ability to generate a correct response to the foundational science content (stored and retrievable). Multiple choice tests storage and attempts to reactivate accessibility (ie, marginal knowledge)

\begin{tabular}{|c|c|c|c|}
\hline $\begin{array}{l}\text { Fill-in-the-blank } \\
\text { Response }\end{array}$ & $\begin{array}{l}\text { Multiple-choice } \\
\text { Response }\end{array}$ & Condition & Meaning and Study Results \\
\hline Correct & - & Retrieval success & $\begin{array}{l}\text { Participants had retrievable knowledge. } \\
\text { Increased potential for near transfer, but unlikely to } \\
\text { significantly influence far transfer success. }\end{array}$ \\
\hline Incorrect & - & Retrieval failure & $\begin{array}{l}\text { Participants did not have retrievable knowledge. They } \\
\text { either had no knowledge or marginal knowledge. } \\
\text { Decreased potential for transfer. }\end{array}$ \\
\hline Incorrect & Correct & $\begin{array}{l}\text { Reactivated marginal } \\
\text { knowledge }\end{array}$ & $\begin{array}{l}\text { Participants had retrieval failure but could recognize } \\
\text { the correct response. } \\
\text { Increased potential for near transfer only. }\end{array}$ \\
\hline Incorrect & Incorrect & - & $\begin{array}{l}\text { Participants had no prior knowledge or were } \\
\text { unsuccessful in reactivation.. } \\
\text { No potential for transfer }\end{array}$ \\
\hline
\end{tabular}

multiple-choice test was well above chance $(33 \%$ with three response options). The correct answer was almost always selected when the student had initial retrieval success (ie, their response to the fill-in-the-blank question was correct) (odds ratio $=4$ [95\% CI: 2.5-6.4] $[p<.001]$ ). If students had retrieval failure, they still performed fairly well on the multiple-choice version of the question. This suggested that students could recognize the correct response but could not generate the correct response, which is indicative of marginal knowledge (information has high storage strength but not readily retrievable). Thus, immediately prior to the course, students could produce answers for only about $35 \%$ of content required for their upcoming course; around 50\% was marginal knowledge in that they were able to recognize it, and the remaining $15 \%$ likely represented new learning. These percentages would be consistent given students reviewed much of this information a few months prior to this assessment.

In experiment 2, student performance on the multiple-choice test was well above chance $33 \%$ with three

Table 2. Performance on the Fill-in-the-Blank Questions on the Foundational Science Content. Data presented as mean percentage correct and standard deviation. Experiment 1 was the far transfer condition (foundational science to pharmacokinetics) and Experiment 2 was the near transfer condition (foundational physiology to application question)

\begin{tabular}{llc}
\hline Experiment & Condition & Mean (SD) \\
\hline 1 (Far Transfer) & Control & $36(21)$ \\
& Experimental & $37(22)$ \\
2 (Near Transfer) & Control & $21(17)$ \\
& Experimental & $25(18)^{\mathrm{a}}$ \\
\hline
\end{tabular}

${ }^{\mathrm{a}} p<.05$ vs control response options). The correct answer was almost always selected when the student had prior retrieval success (odds ratio $=17$ [95\% CI: 11.3-26.2] $(p<.001)$ ). If students had prior retrieval failure, they performed slightly better than chance on the multiple-choice items. Thus, immediately prior to the course, students could produce only about $20 \%$ of content required for their upcoming course; $56 \%$ was marginal knowledge in that they were able to recognize it, and the remaining $24 \%$ likely represented new learning. This suggests a large part of the content was indeed review versus new learning. The review of previously learned concepts, rather than new learning, is the goal of the Pharmacy Bridging Course.

We then asked whether students could transfer their foundational knowledge to novel situations such as pharmacokinetics (far transfer) or to pharmacy-related application of physiology (near transfer) (Figure 2). Experiment 1 tested for far transfer effects and found no significant difference between conditions $(M=47 \%$ vs $48 \%$ ) (Figure 2A). When students had a prior retrieval success, there was no significant difference in performance on the kinetics questions compared to when they had prior retrieval failure $(\mathrm{M}=52 \%$ vs $46 \%, \mathrm{~d}=.20$, $p=.073$ ) (Figure 2A). In summary, prior knowledge (or lack thereof) did not impact student's ability to answer application questions.

In experiment 2, the near transfer study, there was a significant difference in results between control and experimental conditions $(\mathrm{M}=47 \%$ vs $52 \%, \mathrm{~d}=.20, p<.016)$ (Figure 2B) but this probably is a function of the difference in their baseline knowledge assessment. When students had prior retrieval success, they performed much better on the applied physiology questions than if they had 


\section{American Journal of Pharmaceutical Education 2019; 83 (6) Article 6809.}

Table 3. Performance on the Multiple-Choice Questions. Data presented as mean percentage correct and standard deviation. Data presented as a total and conditionalized on whether students got the fill-in-the-blank question correct or incorrect

\begin{tabular}{lll}
\hline Experiment & \multicolumn{1}{c}{ Condition } & $\begin{array}{c}\text { Mean } \\
\text { (SD) }\end{array}$ \\
\hline 1 (Far Transfer) & Total & $78(19)$ \\
& Fill-in-the-blank CORRECT & $91(23)^{\mathrm{a}}$ \\
& Fill-in-the-blank INCORRECT & $71(27)$ \\
2 (Near Transfer) & Total & $56(16)$ \\
& Fill-in-the-blank CORRECT & $93(21)^{\mathrm{a}}$ \\
& Fill-in-the-blank INCORRECT & $44(18)$ \\
\hline
\end{tabular}

${ }^{\mathrm{a}} p<.05$ vs incorrect on the fill-in-the-blank

prior retrieval failure $(\mathrm{M}=68 \%$ vs $44 \%, \mathrm{~d}=.73, p<.001)$ (Figure 2B). That is, students could apply their knowledge to basic physiological problems with a moderate effect $(.2<\mathrm{d}<.7)$

While the previous questions asked whether students could apply their knowledge (knowledge that was both stored and retrievable), our next question was, can students apply their newly reactivated marginal knowledge (Figure 2). For students' knowledge that had a high storage strength but low retrieval strength (ie, marginal knowledge), we stabilized access to this information (ie, reactivated) with the multiple-choice questions. In experiment 1 , given an initial retrieval failure, the chance to answer the question in multiple-choice format did not improve performance on the kinetic application questions $(\mathrm{M}=45 \%$ vs $49 \%$ ) (Figure 2A). Furthermore, there was no benefit of answering the multiple-choice question correctly or incorrectly ( $\mathrm{M}=49 \%$ vs $.46 \%$ ) (Figure $2 \mathrm{~A}$ ). Thus, students could not apply their marginal knowledge to solve pharmacokinetic questions.

In experiment 2, for the reactivated marginal knowledge questions, we again compared that performance to both the control group and to questions that were incorrect on the multiple-choice format after initial retrieval failure. Compared to the control group with initial retrieval failure, a chance to answer the multiple-choice version did not improve performance on the application questions $(\mathrm{M}=43 \%$ vs $46 \%$ ) (Figure $2 \mathrm{~B})$. However, there was a benefit of successfully answering the multiple-choice question correctly compared to incorrectly ( $\mathrm{M}=53 \%$ vs $40 \%$, $d=.31, p<.001$ ) (Figure 2B). Thus, students could apply their marginal knowledge to solve near transfer problems.

At the end of the semester, after formal instruction, we hypothesized that students should be more successful in applying their information to solve problems. Thus, in each experiment, these questions were included on the final examination. In experiment 1 , there was a significant improvement in performance for the control condition
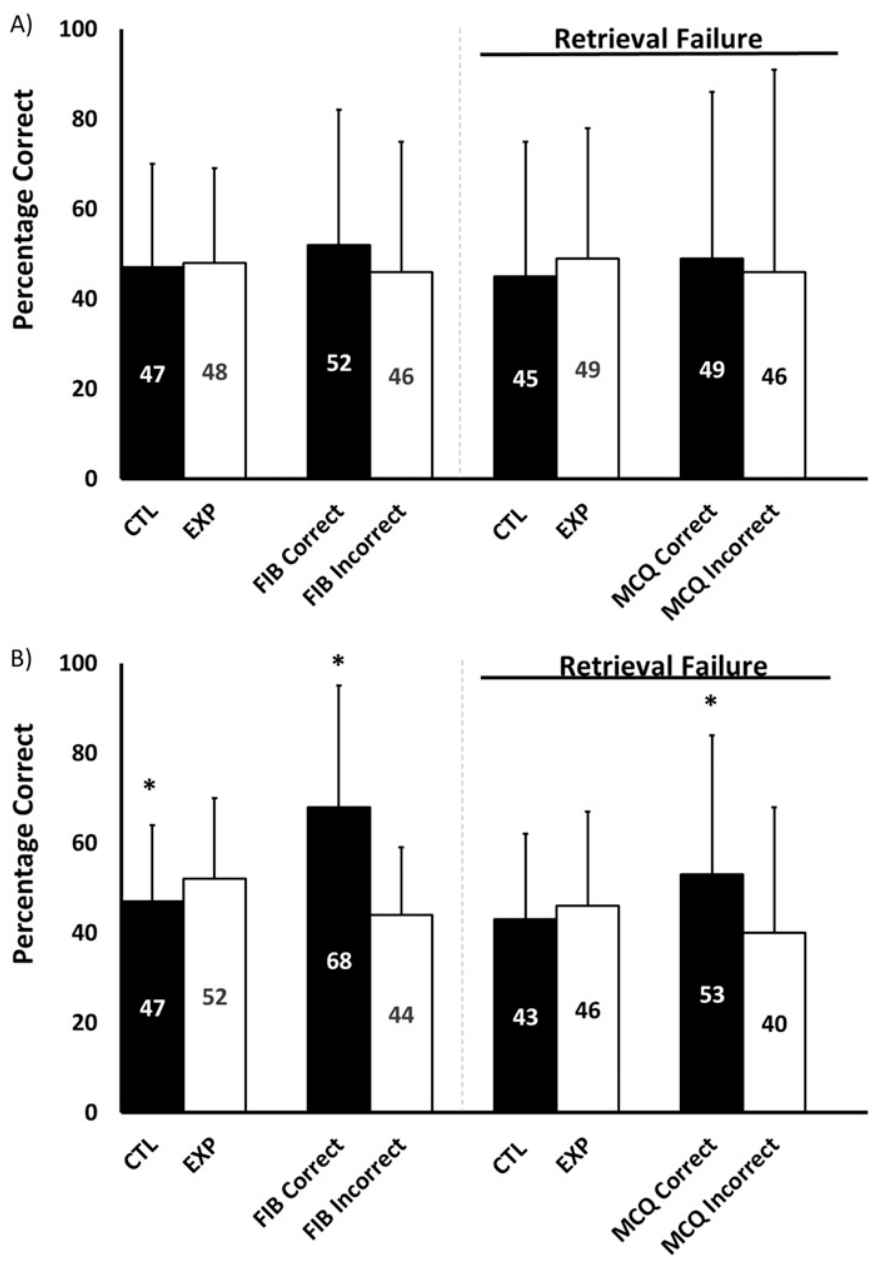

Figure 2. Proportion Correct on the Transfer (Application) Tasks: (A) Far transfer condition (Experiment 1) and (B) Near transfer condition (Experiment 2). CTL = control,

$\mathrm{EXP}=$ experimental group receiving multiple-choice questions, $\mathrm{FIB}=$ fill in the blank, $\mathrm{MCQ}=$ multiple-choice question. Retrieval failure means students could not generate the correct response on the fill-in-the-blank questions on the foundational content. $*=p<.05$ vs respective comparator (white bars). Data presented as mean and standard deviation.

$(\mathrm{M}=47 \%$ vs $78 \%, p<.001)(d=1.0)$ and experimental condition $(\mathrm{M}=47 \%$ vs $78 \%, p<.001)(d=1.1)$. However, there was no difference between the control and experimental conditions on the final examination. Students with initial retrieval success scored the same as those with initial retrieval failure $(\mathrm{M}=78 \%$ vs $79 \%, p=.67)$. Students successful on correctly answering the multiplechoice questions were not significantly different than those who were incorrect ( $\mathrm{M}=77 \%$ vs $74 \%, p=.48$ ). While instruction improved performance, prior knowledge or reactivated marginal knowledge was not influential in far transfer conditions.

In experiment 2 , there was significant improvement after instruction for both the control group ( $M=47 \%$ vs 


\section{American Journal of Pharmaceutical Education 2019; 83 (6) Article 6809.}

$83 \%, p<.001)(\mathrm{d}=1.7)$ and the experimental group $(\mathrm{M}=52 \%$ vs $86 \%, p<.001)(\mathrm{d}=1.7)$. There was a small difference between the control and experimental conditions on the final $(\mathrm{M}=84 \%$ vs $86 \%, p=.048, \mathrm{~d}=.16)$, which is probably a function of differences at baseline for knowledge between conditions. Students with initial retrieval success scored better than those with initial retrieval failure $(\mathrm{M}=90 \%$ vs $84 \%, p<.001)(d=.32)$. Students who successful answered the multiple-choice questions correctly were not significantly different than those who were incorrect ( $\mathrm{M}=87 \%$ vs $83 \%, p=.067)$ $(d=.15)$. Again, instruction improves performance on application, but in this case, prior knowledge may have had some influence.

\section{DISCUSSION}

This study examined students' ability to transfer foundational, prerequisite knowledge and skills to pharmacy application. In experiment 1 , we examined the ability of students to apply foundational concepts in chemistry and physiology to pharmacokinetics, a far transfer condition. Students were unsuccessful in applying their foundational knowledge to a far condition. In experiment 2 , we examined the ability of students to apply physiology concepts to pharmacy application of physiological concepts, a near transfer condition. Students with readily retrievable foundational knowledge (ie, those who were correct in the fill-in-the-blank questions) were more likely to successfully transfer knowledge to near situations compared to students who had non-retrievable foundational knowledge. However, this was a moderate effect. Together, this indicates that students having sufficient baseline knowledge is insufficient for successful far transfer of that knowledge but may be helpful for near transfer.

Our findings suggest that a multiple-choice question may be a sufficient stimulus to reactivate marginal knowledge in student pharmacists and potentially allow the learner to use that information for near transfer tasks. We wanted to know if we increased the accessibility of stored knowledge, could students use this reactivated knowledge and apply it. Students who had their foundational knowledge reactivated by the multiple-choice questions were unlikely to apply that information successfully in the far transfer condition but showed some ability in the near transfer condition. That is, students who could not recall the foundational material on the fill-in-the-blank questions but were correct on the multiple-choice version of the questions could have that information reactivated through the multiple-choice answer but still struggled to apply that information under more challenging circumstances.
At the end of the semester, students were retested on the material they encountered on the first day of class. Students could successfully answer the near (Experiment 2) and far (Experiment 1) conditions after formal instruction on the topic. The success of applying the information seemed to be independent of their initial knowledge base.

This is one of the first studies examining the transferability of foundational science knowledge to pharmacy application, particularly with the transferability of marginal knowledge. A challenge of the study is the guesswork required to establish potential prior knowledge. This is especially true for experiment 2 . Given the variability of prerequisite course content, identifying content that students should have learned is challenging. This was seen with the low performance on fill-in-the-blank questions. This was less of an issue in experiment 1 because the content of the Pharmacy Bridging Course was known. The challenge in experiment 1 was generating application questions that aligned well with the foundational knowledge. Besides the experiment-specific challenges, there are two potential limitations to this study. First, we did not establish that marginal knowledge was reactivated by the multiple-choice questions; instead, we assumed it was reactivated based on prior research. Prior research from our laboratory established that in the classroom setting, multiple-choice testing can stabilize students' ability to access marginal knowledge for a few weeks at minimum. ${ }^{9}$ Second, the application format in the two experiments was different, with experiment 2 having a higher fraction of multiple-choice questions. The study was conducted this way because the format is part of how the course is offered. Ideally, the format should be more comparable.

There are several implications for these findings. First, transfer is difficult for students, and successful learning in prior course work does not guarantee that this information will be remembered over the long-term because students rapidly forget content if they do not continue to use it. ${ }^{12-15}$ This problem occurs even if material was learned well initially. ${ }^{16-18}$ The second implication is that this information may not be completely forgotten. The inability of a student to generate a response may mean it is temporarily inaccessible. As such, it may be prudent for instructors to use a multiple-choice pre-assessment of students' prior knowledge to increase their ability to access this knowledge. The final implication is that knowledge is an important factor in transfer, but by itself is insufficient. Formal instruction that deepens understanding and teaches application is most likely needed to help students apply their knowledge to the relevant pharmacy concepts.

From a practical viewpoint, instructors can do several things to promote transfer to learning. One potential model to help with transfer is the Knowledge-Learning-Instruction 


\section{American Journal of Pharmaceutical Education 2019; 83 (6) Article 6809.}

Framework. ${ }^{19}$ This model defines three learning processes: memory and fluency; induction and refinement; and understanding and sensemaking. Each process has associated instructional principles. As an example, memory and fluency can utilize spacing of practice and testing to increase long-term retention of knowledge and accessibility (ie, fluency). To start though, learners must ensure they have the prior knowledge and that prior knowledge is accessible (ie, retrievable). Baseline multiple-choice questions can both assess knowledge and reactivate the inaccessible knowledge. This may be followed by some remediation to ensure core concepts are well understood. Induction and refinement can be developed with feedback and worked examples. Ideally, learners should be seeing problems from a variety of perspectives, such as using the same drug knowledge to answer a pharmacotherapy question, a medicinal chemistry or pharmacology questions, and a pharmacokinetics question. By solving a variety of problems, students can learn to generalize their knowledge and skills, making them less dependent on context (ie, a specific class or course). Finally, understanding and sense making is facilitated with self-explanation and accountable talk (ie, encouraging students to be accountable to accurate knowledge, rigorous reasoning, and the classroom community). This can be functionalized through peer-teaching strategies (ie, collaborative or cooperative learning) such as problem-based learning or team-based learning to name a couple.

\section{CONCLUSION}

Overall, the results of this study suggest that while some students may be able to transfer their prerequisite knowledge to pharmacy application, most students probably cannot successfully without formal instruction. In addition, reactivating foundational knowledge through multiple-choice testing has been shown to be sufficient to cause retention of the knowledge, but seems to be an insufficient stimulus to allow for transfer to occur. What this confirms is that even if students have the prior knowledge, transfer cannot be assumed to be an automatic process and probably requires specific instruction.

\section{REFERENCES}

1. Dinsmore DL, Baggetta P, Doyle S, Loughlin SM. The role of initial learning, problem features, prior knowledge, and pattern recognition on transfer success. J Exp Educ. 2014;82(1):121-141.
2. Marsh EJ, Roediger HL, Bjork RA, Bjork EL. The memorial consequences of multiple-choice testing. Psycho Bull Rev. 2007;14(2):194-199.

3. Simons PRJ. Transfer of learning: paradoxes for learners. Int $J$ Educ Res. 1999;31(7):577-589.

4. Brown PC. Make It Stick: the Science of Successful Learning. Cambridge, Massachusetts: The Belknap Press of Harvard UP; 2014.

5. Barnett SM, Ceci SJ. When and where do we apply what we learn? A taxonomy for far transfer. Psychol Bull Rev. 2002;128(4):612-637.

6. Ebbinghaus H. Memory: a contribution to experimental psychology. Ann Neurosci. 2013;20(4):155.

7. Bjork RA, Bjork EL. A new theory of disuse and an old theory of stimulus fluctuation. In: Estes WK, Healy AF, Kosslyn SM, Shiffrin RM, eds. Essays in Honor of William K. Estes. Hillsdale, NJ: L. Erlbaum Associates; 1992.

8. Bahrick HP, Hall LK. Preventative and corrective maintenance of access to knowledge. Appl Cogn Psych. 1991;5:1-18.

9. Butler AC, Black-Maeir AC, Campbell K, Marsh EJ, Persky AM. Stabilizing access to marginal knowledge in a classroom setting. Med Educ. In review.

10. Cantor AD, Eslick AN, Marsh EJ, Bjork RA, Bjork EL. Multiplechoice tests stabilize access to marginal knowledge. Mem Cogn. 2015;43(2):193-205.

11. McLaughlin JE, Khanova J, Persky AM, Hathaway N, Cox WC. Design, implementation, and outcomes of a three week pharmacy bridging course. Am J Pharm Educ. 2017;81(7):Article 6313.

12. Custers EJFM. Long-term retention of basic science knowledge: a review study. Adv Health Sci Educ. 2010;15(1):109-128.

13. Custers EJFM, ten Cate OTJ. Very long-term retention of basic science knowledge in doctors after graduation: very long-term retention of basic science knowledge. Med Educ. 2011;45(4):422430.

14. Ling Y, Swanson DB, Holtzman K, Bucak SD. Retention of basic science information by senior medical students. Acad Med. 2008;83(10):S82-85.

15. Persky AM, Wells MA, Sanders KA, Fiordalisi J, Downey C, Anksorus HA. An interdisciplinary approach improving long-term retention of pharmacology knowledge. J Dental Educ.

81(9):1077-1084.

16. Emke AR, Butler AC, Larsen DP. Effects of team-based learning on short-term and long-term retention of factual knowledge. Med Teach. 2016;38(3):306-311.

17. Larsen DP, Butler AC, Roediger IHL. Comparative effects of test-enhanced learning and self-explanation on long-term retention. Med Educ. 2013;47(7):674-682.

18. Terenyi J, Anksorus H, Persky AM. Learning brand namegenerics: impact of spacing of practice. Am J Pharm Educ. 2018;82(1):Article 6179. doi: 10.5688/ajpe6179.

19. Koedinger KR, Corbett AT, Perfetti C. The knowledge-learninginstruction framework: bridging the science-practice chasm to enhance robust student learning. Cognitive Science. 2012;36(5):757-798. 


\section{American Journal of Pharmaceutical Education 2019; 83 (6) Article 6809.}

Appendix 1. Example Questions for the Two Experiments. Experiment 1 [(far transfer condition) (transferring from foundational science content to pharmacokinetics)]. Experiment 2 [(near transfer condition) (transferring from foundational physiology knowledge to application of physiology)].

\begin{tabular}{|c|c|c|c|}
\hline Experiment & Fill in the Blank & Multiple Choice & Application \\
\hline 1 & $\begin{array}{l}\text { The primary way the lung and } \\
\text { respiration system prevent } \\
\text { blood from getting too acidic is } \\
\text { to }\end{array}$ & $\begin{array}{l}\text { The primary way the lungs and } \\
\text { respiratory system prevent } \\
\text { blood from getting too acidic } \\
\text { is to: } \\
\text { A. HYPERventilate } \\
\text { B. HYPOventilate } \\
\text { C. Reabsorb bicarbonate }\end{array}$ & $\begin{array}{l}\text { KF is undergoing a very long surgery under } \\
\text { general anesthesia. She is being } \\
\text { administered isoflurane by inhalation. } \\
\text { This drug is cleared by the liver and } \\
\text { pulmonary excretion. During surgery, KF } \\
\text { undergoes metabolic acidosis due to } \\
\text { hypoperfusion and lactic acidosis. What } \\
\text { will happen to the clearance of isoflurane? }\end{array}$ \\
\hline 2 & $\begin{array}{l}\text { Most digestion occurs in this } \\
\text { segment of the small } \\
\text { intestine? }\end{array}$ & $\begin{array}{l}\text { Most digestion occurs in this } \\
\text { segment of the small intestine. } \\
\text { A. Duodenum } \\
\text { B. Jejunum } \\
\text { C. Ileum }\end{array}$ & $\begin{array}{l}\text { JK receives a roux-en-y gastric bypass, } \\
\text { which requires a small pouch being made } \\
\text { in the stomach and the mid-jejunum being } \\
\text { attached to this newly formed pouch. } \\
\text { What would be the result of this surgery in } \\
\text { terms of digestion, or nutrient absorption? } \\
\text { JK would be at risk for } \\
\text { A. constipation } \\
\text { B. vitamin and mineral deficiencies } \\
\text { C. intestinal bacterial depletion }\end{array}$ \\
\hline
\end{tabular}

